\title{
Técnicas de projetos: uma alternativa ao ensino aprendizagem a partir do tema gerador Educação Ambiental
}

\author{
Projects techniques: an alternative to teaching and learning from the theme generator
} Environmental Education

\author{
L. O. Silva ${ }^{1 *} ;$ E. S. Rodrigues ${ }^{2}$; E. S. Mota ${ }^{2}$ \\ ${ }^{I}$ Centro de Ciências Sociais e Educação/Departamento de Ciências Naturais/Universidade do Estado do Pará,66113- \\ 010,Belém-Pará,Brasil
}

${ }^{2}$ Polo Universitário de Novo Repartimanto/Curso Licenciatura Plena em Ciências Naturais/Universidade do Estado do Pará, 68473-000, Novo Repartimento-Pará, Brasil.

*luelyoliveira@hotmail.com

(Recebido em 08 de abril de 2016; aceito em 28 de abril de 2016)

\begin{abstract}
O ensino das Ciências Naturais mostra-se necessário a vinculação das Tendências Educacionais em prol de um ensino vinculado com a realidade do educando. Mediante este enfoque, procura-se conhecer a concepção dos professores sobre o uso das técnicas de projetos, suas percepções e utilização de novas estratégias que envolvam a presença direta do aluno na construção do conhecimento. Objetiva-se investigar de que forma o uso de técnicas de projetos voltados a Educação Ambiental vinculada ao ensino de ciências podem contribuir no processo ensino aprendizagem. Esta investigação teve como amostra e lócus, cinquenta e seis alunos e duas professoras de uma escola de ensino fundamental do estado do Pará. Questionários e relatos foram utilizados como coleta de dados. De acordo com processo de investigação, percebeu-se a necessidade da utilização de técnicas de projetos que levem os alunos a uma participação efetiva nas aulas e que consigam correlacionar os conteúdos com seu dia-a-dia. Além de que os discentes declararam que a experiência teve grande êxito para sua formação, pois foi possível destacar aspectos presentes da contextualização do ensino, a compreensão justificada de conteúdos bem como a formação de agentes transformadores.
\end{abstract}

Palavras-chave: Ensino de Ciências; Técnicas de Projetos; Tendências de Ensino

The teaching of Natural Sciences has shown it necessary the linkage of educational trends to the advantage of linking teaching with the reality of the students. Through this approach, it seeks to know the teacher's concepts about project techniques, their perceptions and usage of new strategies that involve a direct student presence in the construction of knowledge. The object is to investigate to what form the use of project techniques aimed at Environmental Education linked to science education can contribute to the learning process. The sample and location used in the investigation was fifty-six students and two teachers from a grade school in the State of Para. Questionnaires and reports were used in the collection of data. According to the investigation process, it was perceived the need for using project techniques that lead students to participate effectively in class and be able to correlate the contents with their day-to-day. Beyond this, the students declared the experience had great success to their formation since it was possible to highlight present aspects of the teaching contexts, the justified understanding of contents as well as the formation of change agents.

Keywords: science education, projects techniques, educational trends

\section{INTRODUÇÃO}

É cada vez mais frequente a busca pelos docentes, por metodologias diferenciadas a serem implementadas em sala de aula. Os projetos de ensino surgem como alternativa de aprendizagem que visam proporcionar atividades que enfoquem à interdisciplinaridade e o contexto do educando. A abordagem de técnicas de projetos para o ensino de ciências naturais deverá ser 
trabalhada efetivamente com maior ênfase, pelos profissionais da área, de forma ampla favorecendo o uso de alternativas metodológicas para construção de projetos que aliem teoria e prática arremetida as temáticas sugeridas pelo plano curricular do ensino fundamental.

Assim sendo, cabe a cada docente adequar a sua realidade os assuntos a serem abordados durante todo o ano letivo. Uma maneira eficiente disto ocorrer é através da prática de projetos [1] considerada como um instrumento para o ensino que propicia a relação do aluno com os conhecimentos escolares e não escolares.

Sob esta ótica, deve-se reconhecer a articulação do ensino de ciências mediante a abordagem de temas rotineiros referentes à melhoria da qualidade de vida e do meio ambiente em que os discentes estão inseridos, promovendo a interdisciplinaridade e despertando-os a consciência e sensibilização para as problemáticas sociais.

A temática ambiental é ampla e possibilita um leque de informações para a formação de cidadãos conscientes que sejam capazes de participar de decisões, expressar seu ponto de vista e compreender as razões mediante seus argumentos. Cabe então nesse processo a participação dos profissionais da educação na mediação deste entrelace [2].

$\mathrm{Na}$ atualidade os conceitos e ações sobre meio ambiente tem sido trocados por práticas escolares de educação ambiental mais abrangente, que se diferenciam pela identificação de atitudes responsáveis produzidas pela escola e respaldadas por outros órgãos do poder público.

A dimensão socioambiental traz um sentido de formação política e de cidadania, onde cada um deve exercer seus direitos, deveres assim como, vincular as questões cidadãs à educação ambiental no sentido transformador.

É necessária uma educação ambiental escolar que não apenas diga aos alunos o que deve ser feito, mas que espelhe em suas práticas cotidianas as premissas da sustentabilidade [3].

Portanto, deve-se praticar em sala de aula a educação ambiental trazendo para escola expectativas de construir um espaço educacional consciente sobre uma possível adaptação à sustentabilidade buscando novos hábitos saudáveis de vida.

Nesse sentido, o uso de projetos tendo como tema gerador o meio ambiente pode ser elaborado fora da escola por órgãos governamentais ou não governamentais ou dentro da escola por professores, buscando desenvolvimento de atividades que atendam os propósitos da educação ambiental contribuindo efetivamente para a formação da cidadania [4,5,6].

É visível que a aprendizagem para a cidadania não deve ser vista somente de forma teórica na escola. Esta deve ser promovida de forma mais abrangente, propiciando ao aluno uma vivência da realidade, fortalecendo a experiência educativa criando elo entre teoria e prática dentro e fora da escola.

É comum que diante da falta de compreensão de certa definição, por exemplo, tanto o professor quanto os alunos passem a acreditar que estejam diante de uma verdade absoluta e se sintam incapazes, intelectualmente, de entender algo que parece ser óbvio para os cientistas [7].

Para tal é preciso instigar o caráter dinamizador da ciência em sala de aula, rompendo com o ensino meramente descritivo. Uma estratégia é trabalhar com projetos que possuam técnicas que se moldem a realidade dos alunos, motivando-os a fazer novas descobertas e construir o seu próprio conhecimento.

É comum no ambiente escolar os alunos receberem conceitos predefinidos e não serem instigados à construção de suas próprias concepções, deixando-os alheios a uma aprendizagem meramente decorativa.

Na perspectiva de levar o discente a despertar o interesse pela ciência através de novas formas de ensino situadas nas técnicas de projeto e aguçar a curiosidade dos mesmos para que possam correlacionar teoria e prática nos conteúdos de ciências naturais, cabem a introdução de ferramentas de ensino como possibilidades de facilitar e aproximar os alunos para sua realidade.

Nesse sentido, o presente trabalho teve por objetivo investigar de que forma o uso de técnicas de projetos pela ação docente voltada a educação ambiental podem ampliar o conhecimento dos discentes e contribuir para o processo de ensino de ciências naturais melhorando a aprendizagem dos educandos do $8^{\circ}$ ano do ensino fundamental. 


\section{MATERIAL E MÉTODOS}

A pesquisa foi desenvolvida em uma escola estadual de ensino fundamental no município de Pacajá sudoeste do Estado do Pará, tendo como população, professores e alunos e como amostra, (56) cinquenta e seis alunos do $8^{\circ}$ ano de (2) duas turmas do ensino fundamental e (2) duas professoras da disciplina Ciências. Utilizou-se como instrumento de coleta de dados [8] questionários contendo questões objetivas e subjetivas. O método de análise adotado foi de caráter qualitativo [9].

A investigação deu-se em quatro momentos, sendo o primeiro momento caracterizado pela diagnose dos professores e alunos [10] através do uso de questionários, visando sondagem de conhecimentos prévios sobre as metodologias utilizadas pelos professores e como estas influenciavam a aprendizagem dos discentes, assim como, a utilização de técnicas de projetos como meio didático.

O segundo momento deu-se a partir da apresentação e sensibilização do corpo docente e discente para a temática do projeto, com foco na mudança comportamental dos discentes em relação ao meio ambiente.

O terceiro momento foi marcado pela implementação do projeto de intervenção - construção da horta. Para este momento deu-se a parte prática, com a coleta de materiais encontrados no entorno escolar e posteriormente a construção da horta na escola. O projeto de intervenção "Árvore de soluções: reutilizar para construir" foi criado com o objetivo de incentivar o uso da "técnica de projeto" como metodologia nas aulas de ciências naturais com foco na educação ambiental.

O quarto e último momento ocorreu por meio da aplicação da avaliação somativa [10], aplicada aos discentes com intuito de investigar se os objetivos, foco da pesquisa foram alcançados sobre a experiência da utilização da técnica de projetos evidenciada.

\section{RESULTADOS E DISCUSSÃO}

\subsection{Percebendo o ensino aprendizagem em ciências naturais dos discentes do $8^{\circ}$ ano.}

A aprendizagem em ciências naturais deve estar voltada para a construção do cidadão, onde os alunos tornam-se reflexivos e transformadores, além de agentes desse processo, neste intuito Delizoicov; Angotti; Pernambuco [1], ressaltam que as ciências naturais surgiram com os conhecimentos técnicos desenvolvidos pela intervenção na natureza e pela busca de sua compreensão.

Questionou-se os discentes do $8^{\circ}$ ano acerca da agradabilidade das aulas de ciências, e sobre a clareza dos assuntos explanados, os resultados estão expressos na Tabela 1.

Tabela 1: Opiniões dos discentes quanto agradabilidade e clareza das aulas

\begin{tabular}{lccc}
\hline Pergunta & Sim & Não & Em partes \\
Na sua opinião as aulas de ciências são agradáveis? & $82 \%$ & $18 \%$ & --------- \\
Os assuntos de ciências são ensinados de forma clara? & $76 \%$ & $11 \%$ & $13 \%$
\end{tabular}

Percebe-se que a maioria dos alunos consideram as aulas de ciências agradáveis, afirmação essa, expressa nos $82 \%$ dos alunos que responderam sim à pergunta indicada na tabela 1. Contudo esse percentual diminui para 76\%, quando os mesmos foram indagados sobre a clareza dos assuntos expostos nas aulas de ciências, onde se observa que $13 \%$ acreditam que os assuntos são ensinados de forma clara apenas em partes.

Conhecer as dificuldades dos discentes a partir de suas peculiaridades é uma forma de entender e buscar soluções para minimizar as disparidades sobre os conteúdos ensinados. Os 
Parâmetros Curriculares Nacionais [11] enfocam que, a partir dos reconhecimentos das diferenças existentes entre pessoas, fruto do processo de socialização e do desenvolvimento individual, será possível conduzir um ensino pautado em práticas que sirvam a novos aprendizados.

O cenário das aulas ainda necessita de mudanças metodológicas, visto que nem todos os alunos classificam as aulas como agradáveis de acordo com a tabela 1. Ferreira [12], aponta que a aversão a pressão e autoridade do professor, ou desinteresse da matéria ensinada podem ser provocados pela má escolha dos recursos metodológicos, atrapalhando a forma de ensinar.

A falta de estímulo, participação e interesse podem ser aguçados por metodologias adequadas a realidade do educando, visto que não existe uma receita pronta e acabada, que o docente deve visualizar a necessidade de cada turma, para assim usar a metodologia apropriada, levando o aluno a ser o autor do conhecimento [12].

Morais; Andrade [13] destacam que a ciência deve ser entendida como um processo, uma maneira de conhecer o mundo, que não utiliza um único método e não depende de gênios individuais. Com isso, percebe-se a importância de tornar as aulas prazerosas e dinâmicas, intercalando o aprendizado escolar com o conhecimento já advindo dos alunos, englobando os mesmos em benefício da aprendizagem.

Com a aplicação dos questionários aos alunos, desejou-se também conhecer quais são as metodologias utilizadas e reconhecidas durante as aulas de ciências, o Gráfico 1 expressa esses resultados.

Gráfico 1: Quais são as atividades mais utilizadas nas aulas de ciências?

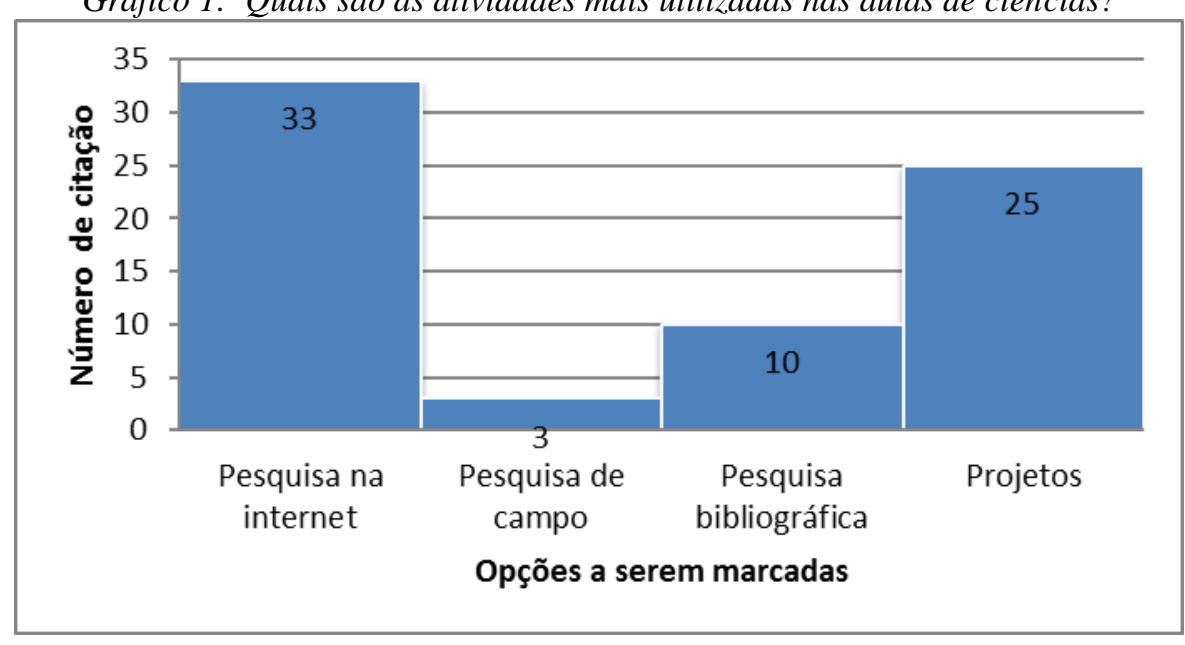

O Gráfico 1, revela que a metodologia em maior ênfase é a pesquisa na internet, além desse método os projetos também são bem evidenciados no processo de ensino do $8^{\circ}$ ano, projetos esses que na sua maioria estão relacionados a datas comemorativas e não a introdução de técnicas diferenciadas que possibilitem a assimilação de concepções construtivas a aprendizagem.

Morais; Andrade [13] enfatizam que a ciência deve ser entendida como um processo, uma maneira de conhecer o mundo, que não utiliza um único método e não depende de gênios individuais. Com isso, pecebe-se a importância de tornar as aulas prazerosas e dinâmicas, intercalando o aprendizado escolar com o conhecimento já advindo dos alunos, englobando os mesmos em benefício da aprendizagem.

Os autores ainda explicitam que:

A mobilização pelos alunos de suas ideias previamente construidas sobre conceitos das ciências pode fazer com que as estratégias didáticopedagógicas utilizadas pelo professor produzam efeitos inesperados e muitas vezes inadequados em relação aos objetivos do ensino de ciências... portanto, é importante que o professor conheça essas concepções e que, para mobilizá-las, planeje oportunidades por meio 
das quais possam ser reconhecidas pelos alunos e também desafiadas de maneira explícita e intencional pelos conceitos científicos [13].

Quanto as atividades de campo, o ensino fora da sala de aula oferece e oportuniza práticas interdisciplinares onde pode-se trabalhar vários temas, porém estas devem ser discutidas e planejadas para que os alunos alcancem um bom desempenho, visto que os mesmos terão contato com uma grande diversidade de informações $[14,15]$.

Ainda no questionário aplicado aos alunos desejou-se conhecer quais recursos utilizados pelas professoras durante as aulas de ciências. As respostas obtidas foram descritas no Gráfico 2.

Gráfico 2 - Recursos didáticos utilizados pelas professoras

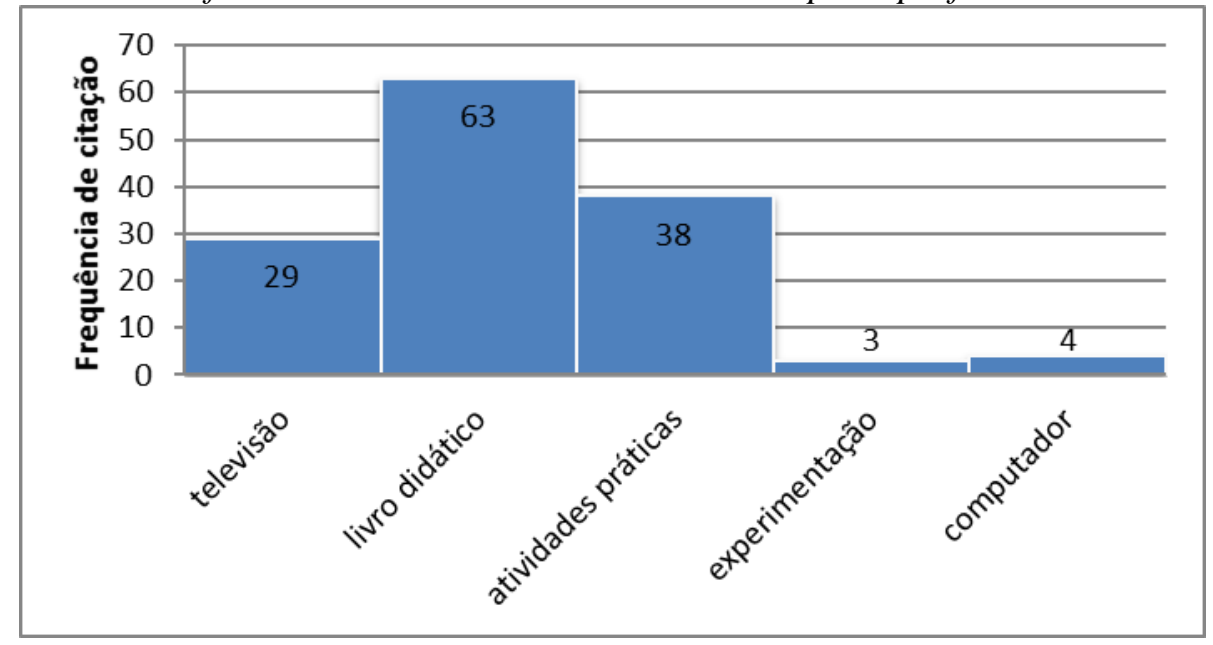

Dentre os diversos recursos disponíveis para o ensino de ciências, a perquisa revela que o livro didático ainda é o recurso mais utilizado, seguido das atividades práticas. Estas por sua vez, tem como principal característica a flexibilidade que propicia uma contextualização dos conteúdos dando oportunidade para realizar a busca e a consolidação de conhecimentos adquiridos ou trazer novos desafios [13].

Percebe-se também que o uso de equipamentos tecnológicos também fazem parte da rotina pedagógica das docentes. Os PCNs [11], diz que a associação entre ciência e tecnologia se amplia tornando-se mais presente no cotidiano, modificando cada vez mais o próprio mundo.

Pela análise fica evidente o uso da televisão, tendo em vista a utilização nas aulas como forma de dinamizar o ensino. O uso do computador e da televisão é considerado como um meio de alcançar melhorias na educação, oferecendo suporte para aprimorar o perfil de formação dos educandos, consequentemente contribuindo para o desenvolvimento cultural, social e econômico do país [12].

\subsection{Percebendo a prática docente no ensino aprendizagem em ciências naturais do $8^{\circ}$ ano.}

As professoras participantes da pesquisa possuem mais de oito anos de docência, sendo uma Licenciatura em Biologia e a outra em matemática cursando Ciências Naturais.

Através de questionário aplicado, as mesmas relataram que nunca receberam curso de formação continuada, mas que procuram fazer uso sempre que possível dos materiais didáticos que a escola disponibiliza como: vídeos em DVD, televisor, revistas, dorso, esqueleto humano e Data show, ressaltaram ainda que alguns dos materiais os quais usam em sala foram adquiridos com recursos próprios.

As docentes inquiridas afirmam que as metodologias utilizadas para trabalhar os conteúdos de ciências têm facilitado à aprendizagem, e que os alunos apreciam os temas trabalhados no $8^{\circ}$ ano, por se tratar de conceitos relacionados à alimentação e o corpo humano. 
Questionou-se as professoras sobre o uso de tendências educacionais em suas práticas docentes, as respostas estão ilustradas na tabela 2 .

Tabela 2: Tendências Educacionais mais utilizadas na prática docente?

\begin{tabular}{lcc}
\hline Tendências Educacionais utilizadas & Professora 1 & Professora 2 \\
Ciência Tecnologia e Sociedade (CTS) & Não & Sim \\
Pesquisas & Sim & Sim \\
Temas Transversais & Sim & Sim \\
Abordagens Temáticas & Não & Sim \\
Projetos & Não & Sim \\
Experimentação & Não & Sim \\
\hline
\end{tabular}

De acordo com a tabela 2 as duas docentes utilizam temas transversais e pesquisa, e somente uma professora utiliza as demais tendências sugeridas na tabela. Destaca-se também, que as mesmas declaram que o uso dessas tendências não era de forma frequente.

No processo educacional deve-se buscar através do planejamento diversas técnicas que possibilitem ou tragam novas formas de construção do conhecimento e que englobem os discentes a uma visão científica social com a finalidade de se construir um processo de ensino e aprendizagem significativo.

É importante construir uma relação de interdependência entre ensino e aprendizagem. Este processo é auxiliado pelas metodologias de ensino, as quais apresentam roteiros para diferentes situações didáticas, conforme a tendência/corrente pedagógica adotada pelo professor, de forma que o aluno se aproprie dos conhecimentos propostos e/ou apresente seus conhecimentos prévios para que possam ser transformados em conhecimentos científicos. Logo, as atividades metodológicas desenvolvidas devem ser combinadas, oferecendo ao aluno a oportunidade de perceber e analisar o assunto sob diversos ângulos [16].

Nesse aspecto, é importante a conexão tanto das metodologias como das práticas a serem executadas, pois isso irá garantir o bom andamento do processo de ensino e do conhecimento a se transpor. O planejamento e o acompanhamento contínuo garantirão o sucesso deste.

É importante salientar que mesmo mencionando o uso de várias tendências uma das professoras relatou que esse uso é esporádico, devido a grade curricular que deve ser cumprida anualmente, quando indagada sobre o uso de atividades práticas a mesma demonstrou, em seu relato, a não preocupação em utilizá-las.

Outro questionamento realizado as docentes investigadas foi sobre a implantação da técnica de projetos no ambiente escolar, onde se desejou saber se as docentes saberiam trabalhar a proposta dos projetos. A esse questionamento a pesquisa apontou que as mesmas estão prontas para lidar com essa tendência de ensino. Esta surge como, uma alternativa de ensino e de aprendizagem, objetivando a aproximação da realidade do aluno com a escola, o que leva a caracterização e a junção com a pesquisa construindo o chamado conhecimento aberto [13].

Ainda conforme a análise do questionário aplicado é percebível que as professoras acham importante que o sujeito seja capaz de transformar seu conhecimento, para que o próprio se torne o precursor no seu desenvolvimento educacional. Transcrevendo uma resposta "introduzir novas 
formas de ensinar traz benefícios ao processo educacional e melhora o desempenho dos alunos, estes se tornam construtores de seus saberes" (declaração de uma das professoras).

Quando indagadas sob a forma de avaliar os alunos, as docentes dizem fazer uso de questionamentos orais, estudo dirigido, debates, teste escrito. Uma das docentes investigadas relatou fazer uso de aulas práticas rotineiramente. Os PCNs [11] descrevem que "a avaliação deve considerar o desenvolvimento das capacidades dos alunos com relação à aprendizagem de conceitos, de procedimentos e de atitudes. Explanar sobre esta não é simples, pois cada professor deve analisar a realidade ao qual se insere e observar qual melhor maneira de verificar a aprendizagem".

É visível a preocupação relacionada à avaliação, porém deve-se ser ciente que esta deverá ocorrer em diversos momentos, no decorrer do processo e não somente no fim de uma etapa, percebendo sua importância temporalmente, considerando o modo de visualização de cada aluno com o assunto [17].

\subsection{Analisando a avaliação somativa}

O projeto horta na escola foi uma proposta de técnica de projeto realizada para que metodologias de ensino de ciências possam relacionar e ampliar de forma somativa o processo direcionado a investigar os docentes e discentes sobre o uso de projeto e sua importância na aprendizagem. Na aplicação da avaliação somativa os discentes citaram ter conhecido melhor a valorização e preservação do meio ambiente, a reutilização de materiais, a produção e cultivo de alimentos orgânicos, a importância de uma alimentação saudável, o respeito ao próximo, bem como conceitos e ações de sustentabilidade.

Neste sentido, a educação ambiental deve ser estimulada e encorajada por todos que fazem parte da Educação, pelos órgãos públicos e privados, para contribuir com uma sociedade voltada para o desenvolvimento sustentável, pois trata-se de um processo de formação permanente que implica em uma profunda mudança de valores, em uma nova visão de mundo, o que ultrapassa $o$ estado conservacionista [18]

Ainda na abordagem feita, quando indagados: A partir do trabalho desenvolvido no projeto você consegue relacionar com os assuntos da sala de aula e de seu cotidiano? 98\% dos discentes, afirmaram que sim, nas ações de reutilização de pneus e garrafas pets para o cultivo de hortaliças, frutas e leguminosas o qual proporcionou a prática das ações conceituais aprendidas na sala de aula.

A prática de projetos envolve à necessidade do trabalho voltado para formação cidadã, logo as instituições de ensino devem preparar-se para oportunizar um ensino interdisciplinar que abrace a contextualização dos conteúdos escolares levando estes a compreenderem a vivência social em sua totalidade conduzindo os discentes a tornarem-se pesquisadores [19].

É importante saber reconhecer que os alunos são sujeitos de sua aprendizagem e não apenas receptores de conhecimento, que são capazes de assimilar e desenvolver atividades. Delizoicov; Angotti; Pernambuco [1] "relata que devemos reconhecer que esse aluno é, na verdade, o sujeito de sua aprendizagem; é quem realiza a ação, e não alguém que sofre ou recebe uma ação".

Nesse sentido o entrelace entre as disciplinas bem como as trocas de informações devem ser hábitos corriqueiros e que se façam presentes no meio educacional, visando desenvolver técnicas que melhorem a aprendizagem de disciplinas tidas como críticas na escola e estabeleçam uma correlação entre os temas trabalhados dentro da escola e os vivenciados fora dela

Questionou-se ainda aos discentes: A respeito do que foi aprendido no projeto, você consegue levar para o seu meio e lá transmiti-lo? Todos responderam que sim, pois se sentiram capazes de transmitir os conhecimentos até então adquiridos e colocá-los em prática não somente em casa, mas na comunidade ao qual estão inseridos, comprovado pelo depoimento transcrito de um dos discentes investigados: "Sim, pois aprendi e posso ensinar para outras pessoas, porque reutilizar é muito legal para nós e para o meio ambiente, porque é saudável". (Trecho retirado da avaliação somativa).

Ao descrever suas experiências com o projeto os alunos responderam de forma geral ter sido muito boa, pois aprenderam a reutilizar, cultivar, consumir alimentos saudáveis, economizar, 
pesquisar, trabalhar em grupo o que por consequência aguçou o sentido cooperativista dos mesmos. Neste sentido Krasilchik; Marandino [20] relatam:

$\mathrm{O}$ aprendizado deve estar ligado ao dia-a-dia. "Aprender a viver juntos, aprender a viver com os outros" envolve a realização e a profissionalização de projetos comuns por grupos de composição variada, a compreensão e a aceitação de diferenças e de semelhanças que permitem reconhecer a unicidade da espécie humana, cuja sobrevivência depende da cooperação para superar conflitos e resolver problemas locais, regionais e universais [20].

A aquisição de conhecimento se mostra eficaz através da prática de projetos, uma vez que proporciona aprendizados através de interações, levando-os a conviver e respeitar a diversidade cultural, reconhecendo-se como parte integrante deste processo.

É importante que os conteúdos estudados na sala de aula estejam cada vez mais próximos da linguagem que os discentes possuam, aproveitando este fato de forma positiva para a mobilização e construção de cidadãos [21].

\section{CONCLUSÃO}

A partir da investigação é possível fazer considerações ao uso de técnicas de projetos em Educação Ambiental, na perspectiva de contribuir metodologicamente para mudanças de paradigmas na forma em que se processa o ensino de ciências na atualidade. Para este fim, a abordagem do projeto "Árvore de soluções: reutilizar para construir", mediante o trabalho com a horta escolar com a reutilização de materiais enfatizados na temática ambiental e a sustentabilidade, possibilitou a interação de ações coletivas para o fim comum, envolvendo as tomadas de decisões, vinculadas a pesquisa e experiências de vida.

$\mathrm{Na}$ pesquisa evidenciou-se a necessidade de diversificar de forma mais frequente o uso de alternativas metodológicas para o ensino de ciências, bem como consolidar o processo de formação continuada dos professores. Acreditando que assim, os alunos terão oportunidade de vivenciar diversas formas de se contemplar a ciência e sua consequente aprendizagem.

O contato com a metodologia da técnica de projetos evidenciou alternativas opostas a tradicional forma de transmitir conteúdo dentro e fora do ambiente escolar, percebendo os saberes de forma a propiciar atividades educativas que abordem causas, consequências e soluções de problemas oriundos da realidade a qual os alunos estão inseridos.

A forma de abordagem de temas para o ensino de ciências deve ser preparada de modo a proporcionar metodologias e estratégias que sirvam para o docente como uma tentativa de oferecer oportunidades em ações diversificadas de saberes, mediante a socialização de ideias advindas do cenário educativo do aluno, que se complementam ou se modificam a medida que se processa o ensino.

Portanto, as técnicas de projetos evidenciam e aprimoram o modelo de ensino, de organização do espaço sociocultural, oportuniza a reflexão crítica do aluno, testa experiências e limites no processo da aprendizagem em ciências na Educação Ambiental, aborda a realidade, ensina para a formação cidadã levando a uma nova perspectiva de produção do conhecimento, são expectativas reais do trabalho docente diante das novas potencialidades da abordagem científica no ensino e aprendizagem.

\section{REFERÊNCIAS BIBLIOGRÁFICAS}

1. Delizoicov D, Angotti JA, Pernambuco MM. Ensino de Ciências: fundamentos e métodos: São Paulo: Cortez, 2009, 366p.

2. Reis MFCT. Educação Ambiental no Brasil. A inserção da educação ambiental na escola. In.: BRASIL, Ministério de Educação. Salto para o futuro. Brasília, 2008. 54 p. 
3. Brasil MEC. Ciências Ensino Fundamental: Coleção explorando o Ensino. Vol. 18/ Secretaria de Educação Básica. Brasília. 2010. 212 p.

4. Valentin L. Projetos de educação ambiental no contexto escolar: concepções e práticas. Dissertação (Mestrado em Educação) - Universidade Estadual Paulista “Júlio de Mesquita Filho", Rio Claro, 2005. $175 \mathrm{p}$.

5. Terossi MJ. Projetos de educação ambiental da Universidade Livre do Meio Ambiente (UMASQ): concepções e práticas. Dissertação (Mestrado em Educação) - Universidade Estadual Paulista "Júlio de Mesquita Filho", Rio Claro, 2009. 179 p.

6. 21. Almeida FP. Projetos de educação ambiental e seu desenvolvimento na escola pública: concepções e práticas de professores de ciências. Dissertação (Mestrado em Educação) - Universidade Estadual Paulista "Júlio de Mesquita Filho", Rio Claro, 2005. 189 p.

7. Bizzo N. Ciência: fácil ou difícil? 1 $1^{a}$ edição. ed. Biruta. São Paulo, 2010. 154 p.

8. Teixeira E. As três metodologias: academia, da ciência e da pesquisa. 1. Ed. Belém: Ed. Cejup, 1999. $118 \mathrm{p}$.

9. Lüdker M. Pesquisa em educação: abordagens qualitativas. São Paulo: EPU, 1986.

10. Hoffmann J. Avaliação: mito e desafio; uma perspectiva construtivista. 21. ed. Porto Alegre, Mediação, 1996. $115 \mathrm{p}$.

11. Brasil MEC. Parâmetros Curriculares Nacionais: Introdução ( $1^{\circ}$ e $2^{\circ}$ ciclos). Vol. $1 /$ Secretaria de Educação Fundamental. - Brasília: MEC/SEF, 1997. 138 p.

12. Ferreira RGS. "Gestão de Sala de Aula". Ed. CPT. Viçosa, Minas Gerais, 2011. p.100.

13. Morais MB, Andrade MHP. Ciências Ensinar e Aprender. Belo Horizonte: Ed. Dimensão, 2009, 128p.

14. Viveiro AA, Diniz RES. Atividades de campo no ensino das ciências e na educação ambiental: refletindo sobre as potencialidades desta estratégia na prática escolar. Ciência em tela. Vol 2. Número 1, 2009. $12 \mathrm{p}$.

15. Fernandes JAB. Você vê essa adaptação? A aula de campo em ciências entre o retórico e o empírico. Tese (Doutorado em Educação) - Faculdade de Educação, Universidade de São Paulo, São Paulo, 2006. $326 \mathrm{p}$.

16. Evangelista YSP, Chaves EV. Ensino de química: metodologias utilizadas e abordagem de temas transversais. 2012.

17. Campos CC, Nigro G. Teoria e prática em ciências na escola: o ensino-aprendizagem como investigação: volume único, 1. Ed. São Paulo: FTD, 2009. 160 p.

18. Dias GF. Educação Ambiental: princípios e práticas. 8 ed. São Paulo: Gaia, 1993. 400 p.

19. Teixeira PMM. Educação científica e movimento C.T.S no quadro das tendências pedagógicas no Brasil. v.3, n.1. Agost. 2003. Disponível em: < ufpa.br/ensinofts/artigos2/v3n1a7.pdf>. Acesso em: 20 de abril de 2013. $15 \mathrm{p}$.

20. Krasilchik M, Marandino M. Ensino de ciências e cidadania. São Paulo: Moderna, 2007. 87 p.

21. Pereira MG, Rocha GSDC, Barbosa AT. Projetos de ensino: possibilidades para ensinar e aprender em ciências e biologia. V Colóquio Internacional "Educação e Contemporaneidade". São Cristovão, 2011. 